\title{
XLI. Experiments on the elasticity of wires
}

\section{H.E. Wimperis B.A.}

To cite this article: H.E. Wimperis B.A. (1900) XLI. Experiments on the elasticity of wires , Philosophical Magazine Series 5, 50:305, 416-420, DOI: 10.1080/14786440009463931

To link to this article: http://dx.doi.org/10.1080/14786440009463931

曲 Published online: 21 Apr 2009.

Submit your article to this journal

Џ Article views: 3

Q View related articles $₫$ 
the three 3-ohm coils to the bridge is different. It is easy to do this thus:-Let the resistance between each of the adjacent cups, such as I to A, A to B, B to C \&c. be $y$ ohms. Then the resistances of the 3-ohm coils in the multiple are position are $3+\alpha+2 y, 3+\beta+4 y$, and $3+\gamma+6 y$ respectively, and neglecting squares of small quantities as before, we have

$$
\mathrm{B}=1+\frac{1}{9}(\alpha+\beta+\gamma+12 y) .
$$

While the series value of the coils is easily seen to be

$$
\begin{aligned}
\mathrm{B}^{\prime} & =9+\alpha+\beta+\gamma+9 y \\
& =9 \mathrm{~B}-3 y .
\end{aligned}
$$

The value of $y$ is found by connecting I. and II. to the bridge, short-circuiting the other gap of the bridge and then short-circuiting in turn $\mathrm{AA}^{\prime}, \mathrm{BB}^{\prime}, \mathrm{CC}^{\prime}$, and finding a series of balance-points. The difference of the readings thus found gives $a$. In the case of the apparatus used the mean of a number of readings gave

$$
a=\cdot 4 \text { bridge-wire divisions }=.00002 \mathrm{obms} \text {. }
$$

So that instead of putting $\mathrm{B}^{\prime}=9 \mathrm{~B}$ in reducing the results it would have been more accurate to write $B^{\prime}=9 \mathrm{~B}-\cdot 00006$. The correction is too small to be of importance. I also found that at a temperature of $16^{\circ}$ the value of the $3-\mathrm{ohm}$ coils were respectively $3 \cdot 0038,3 \cdot 0026$, and $3 \cdot 0027$.

XLI. Experiments on the Elasticity of Wires. By H. E. Wimperis, B.A., Whitworth Scholar, Late Salomons and Foundation Scholar of Caius College, Cambridge, Demonstrator in the University Engineering Laboratory*.

IN the Philosophical Magazine for February $1900 \mathrm{Mr}$. G. F.C. Searle described an apparatus he had usedito determine some elastic constants for wires of different metals. One very curious result which he obtained was that the value of Poisson's ratio found for certain metals was greater than $\frac{1}{2}$, notably in the case of copper whether hardened or annealed.

Mr. Searle's deduction was that "wires of these four substances (copper, nickel, platinoid, and german-silver) are so far from being isotropic, that it is improper to apply the theory of isotropic solids to them."

It was suggested to the author by Professor Ewing that it

* Communicated by the Author. 
would be of interest to extend these experiments to wires of larger diameter; this suggestion was followed with results appended below.

In the author's experiments six different wires were used (one of which was hollow), of diameters varying from $\frac{3}{10}$ inch to $\frac{1}{4}$ inch. These diameters are greater than those measured by Mr. Searle (which were from $\frac{1}{25}$ inch to $\frac{1}{16}$ inch), thus necessitating a much larger apparatus-the moment of inertial of the vibrating rods being over six times as great.

It is not necessary to repeat the mathematical theory given by Mr. Searle, but the apparatus is shown in fig. 1.

Figr. 1 .

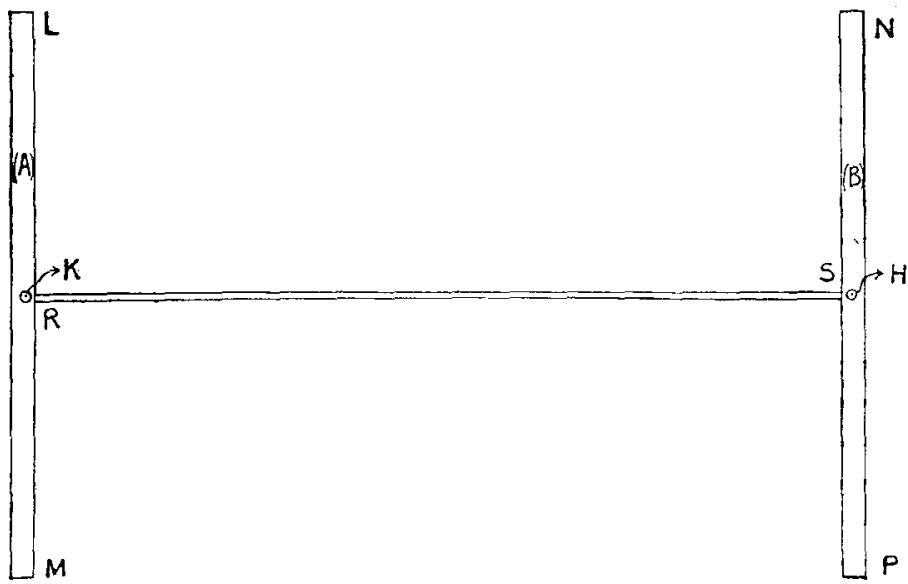

$\mathrm{NP}$ and LM are square bars with holes drilled at $\mathrm{R}$ and $\mathrm{S}$ to admit the wire under test at RS. $H$ and $K$ are two $\frac{\pi}{16}$-inch screws by means of which the vibrating wire is clamped and the apparatus supported.

The method of experiment is as follows:-The apparatus is suspended so that the two swinging bars are in a horizontal plane; the ends at $M$ and $P$ are next inclined to each other and tied with strong cotton-thread. When the apparatus bas come to rest, this thread is burnt and the number of swings per second is estimated by timing a convenient number with a stop-watch. The period so obtained is called $t_{1}$.

It is an important experimental point that, owing to nonuniformity of diameter in the wire under test, the two rods should be rotated relative to the wire through $90^{\circ}$, and a re-determination of $t_{1}$ made. In the following experiments 
this plan was adopted and the results are given: very little variation was found.

The next step is to clamp one rod horizontally and allow the other to hang down below, the under one is then slightly rotated-so twisting the wire-and released. The period of this vibration is also found, and called $t_{2}$.

Here again a re-determination is made by turning the appa. ratus upside down; this corrects variations in the moment of inertia of the rods. thus :-

The constants of the apparatus were carefully determined

$B a r A$.

Weight $=2.932 \mathrm{lb}$.

Length $=18 \cdot 50$ inches.

Breadth $=0.756$ inch.

(Mean of four measurements.)

Depth $=0.763$ inch.

(Mean of four measurements.)

Moment of

$$
\left.\begin{array}{l}
\text { Inertia } \\
\text { Int }
\end{array}\right\}=0 \cdot 2167
$$

Mean value of $\mathrm{K}=0 \cdot 2169$.
Bar $B$.

$=2.936 \mathrm{lb}$.

$=18.50$ inches.

$=0.755$ inch.

$=0.763$ inch.

$=\cdot 2170$

The formulæ given by Mr. Searle are:-

$$
\begin{aligned}
& \mathrm{E}=\frac{8 \pi \mathrm{K} l}{t_{1}^{2} a^{4}}(1+\alpha) ; \quad \mathrm{N}=\frac{8 \pi \mathrm{K} l}{t_{2}^{2} a^{4}} ; \\
& \overline{\mathrm{N}}=\frac{t_{2}{ }^{2}}{t_{1}^{2}}(1+\alpha) \quad \text { and } \quad \sigma=\frac{\mathrm{E}}{2 \mathrm{~N}}-1 .
\end{aligned}
$$

Where $\alpha=\frac{m l^{2}}{60 \mathrm{~K}}=$ correction for mass of wire,

$\mathrm{E}=$ Young's modulus,

$\mathrm{N}=$ modulus of rigidity,

$\mathrm{K}=$ moment of inertia of bars,

$l=$ length of wire,

$a=$ radius of wire,

$\sigma=$ Poisson's ratio,

$m=$ mass of wire.

Fig. 2 shows the method of suspension in the first part of the experiment.

CD is a part elevation of one rod suspended from a cord at $H$. $E$ is the $\frac{5}{16}$-inch screw which screws into a bole in the top of the rod and grips the wire at G. The under part of 
the wire is placed on the top of the screw F and adjusted to the centre of the bole. The surface of the lower screw where it grips the wire is filed to a $V$-notch; this increases the hold and allows of alignment.

Fig. 2.

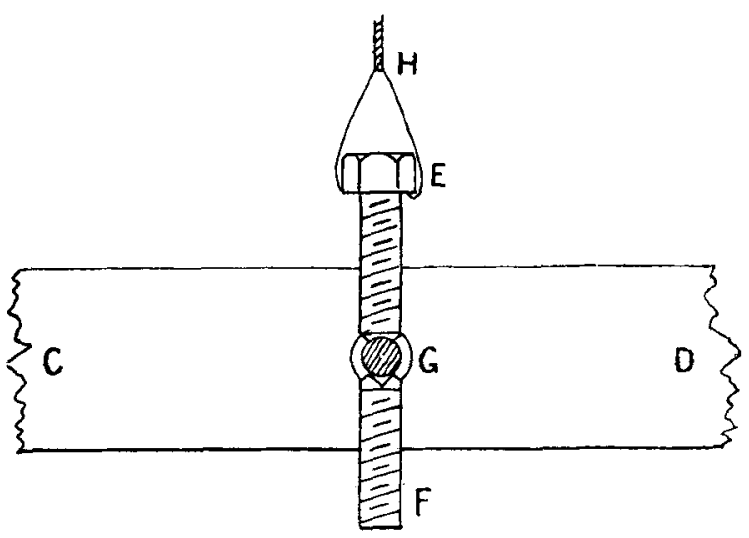

In all cases a considerable number of swing-swangs were recorded, the number varying from 70 to 700 according to the period, and the mean taken.

For convenience, the four periods determined will be referred to as the two horizontal periods and the two vertical periods.

The following table contains the results obtained for each wire, the diameter given in every case is the mean of 10 measurements ; the length is measured between the centres of the grips.

It will be noticed that in no case was a value of Poisson's ratio found greater than $0 \cdot 461$; this, in view of the fact that Mr. Searle obtained several values above 0.5 , is of interest as illustrating a possible effect of the increase in diameter of the wires used.

In conclusion the author wishes to thank Professor Ewing both for advice and the use of the different materials provided. The above experiments were carried out in the Engineering Laboratory at Cambridge. 


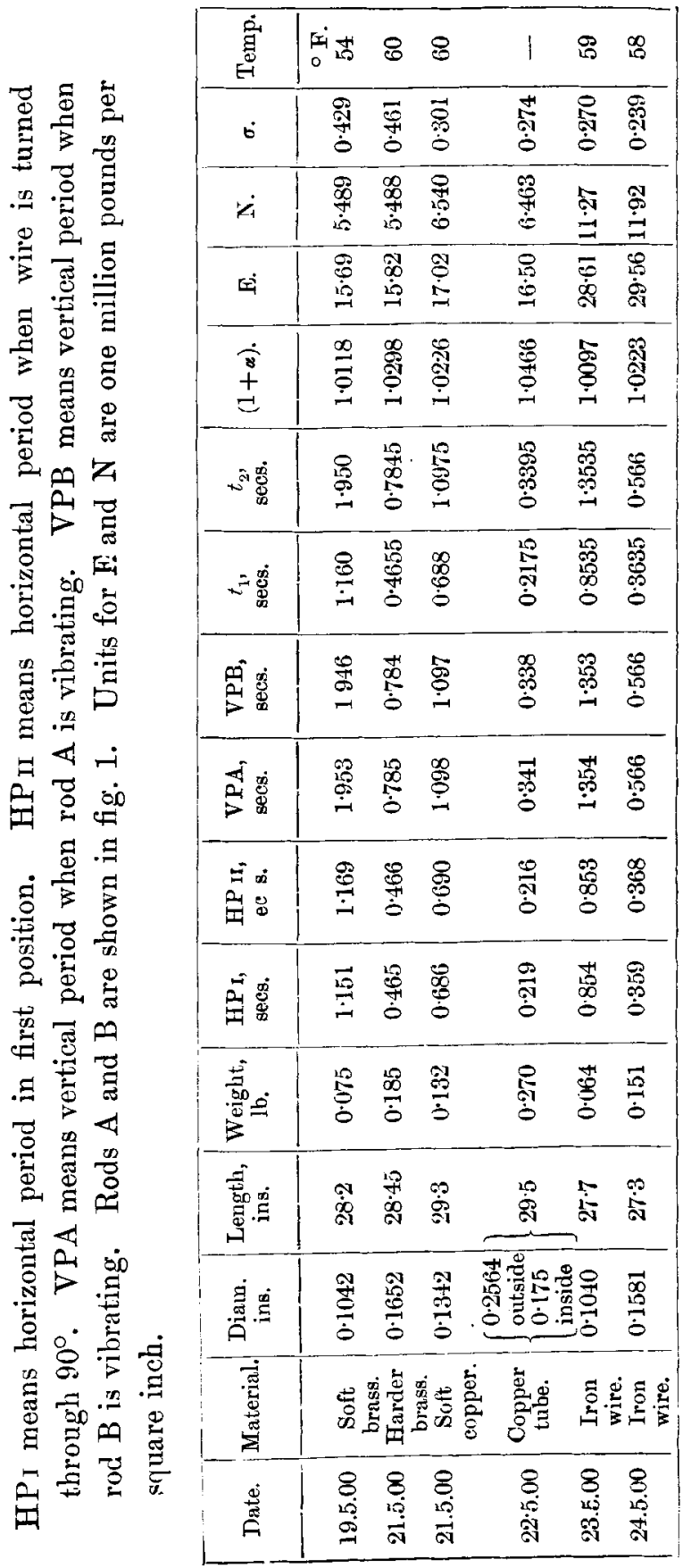

